\title{
Flij ou Flidj
}

(plur. Felja)

\section{Gast}

\section{OpenEdition}

\section{Journals}

Édition électronique

URL : http://journals.openedition.org/encyclopedieberbere/1943

DOI : $10.4000 /$ encyclopedieberbere.1943

ISSN : 2262-7197

\section{Éditeur}

Peeters Publishers

\section{Édition imprimée}

Date de publication : 1 février 1998

Pagination : 2855-2857

ISBN : 2-85744-994-1

ISSN : $1015-7344$

\section{Référence électronique}

M. Gast, « Flij ou Flidj », Encyclopédie berbère [En ligne], 19 | 1998, document F29, mis en ligne le 01 juin 2011, consulté le 24 septembre 2020. URL : http://journals.openedition.org/encyclopedieberbere/1943 ; DOI : https://doi.org/10.4000/encyclopedieberbere.1943

Ce document a été généré automatiquement le 24 septembre 2020.

(c) Tous droits réservés 


\section{Flij ou Flidj}

(plur. Felja)

\section{Gast}

1 Mot arabe qui signifie "brèche-dent", d'après L. Golvin 1950, aflidj en tamazight (Maroc central).

2 Ce terme désigne une bande de tissage à poil ras, de plusieurs mètres de long et de 50 à $90 \mathrm{~cm}$ de large, d'environ $3 \mathrm{~mm}$ d'épaisseur, réalisé sur le métier horizontal fixé à terre, utilisé par les nomades. Le poil qui sert à fabriquer les fils de tissage du flij est tiré de la laine (la plus grossière) de mouton; il est renforcé de poils de chèvre et de chameau selon les disponibilités de ces produits. Connu depuis la Mongolie, l'Afghanistan, la Turquie, la Péninsule arabique jusqu'au sud du Maroc, le métier à terre, de mise en œuvre rapide et facile, est essentiellement lié à la vie nomade et à l'élevage du mouton à laine. Introduit au Maghreb et au Sahara par les tribus hilaliennes au vi ${ }^{\mathrm{e}}$ siècle, il n'a pu atteindre le pays touareg, ni le Sahel africain où dominent l'élevage de la chèvre et du mouton à longues pattes ovis longipes pratiquement dépourvu de laine. 
Fabrication d'un flij décoré (melgût) dans la tribu des el Araâ

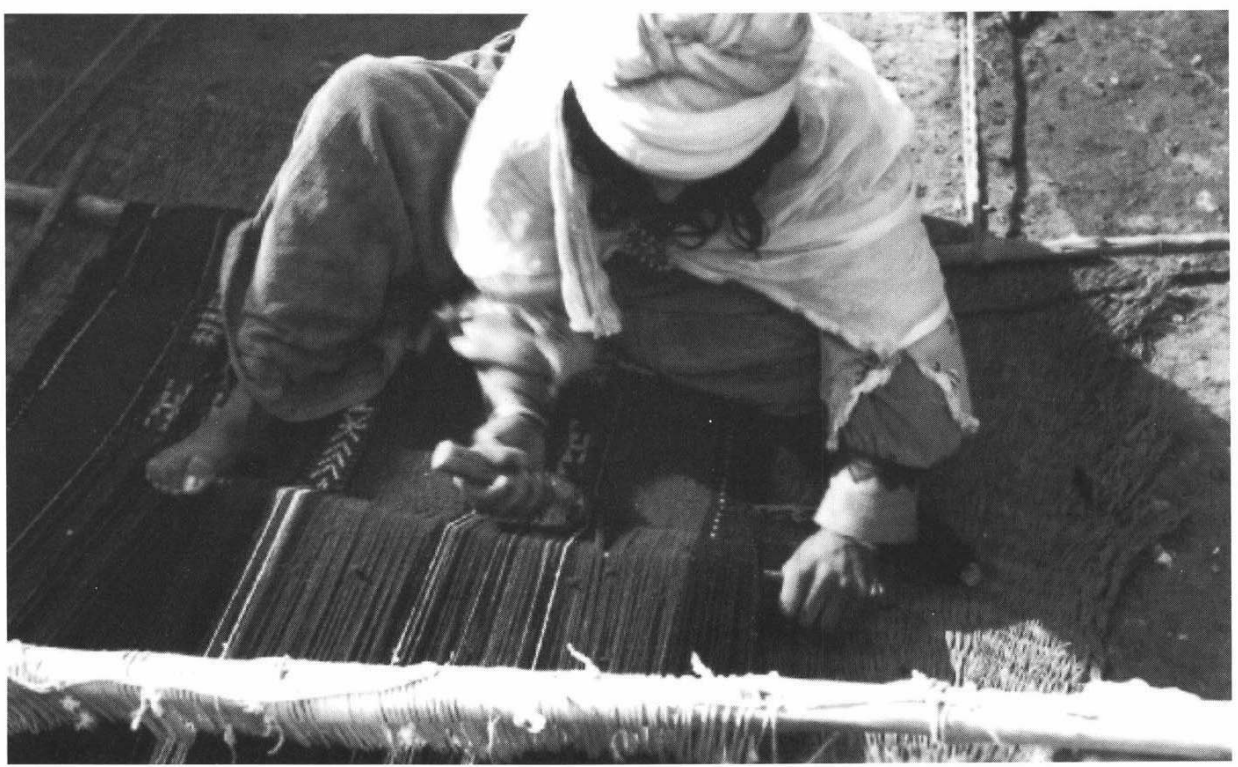

(photo Y. Bonète).

Grande tente de la tribu des Ouled Mimoun dans le Djebel Amour

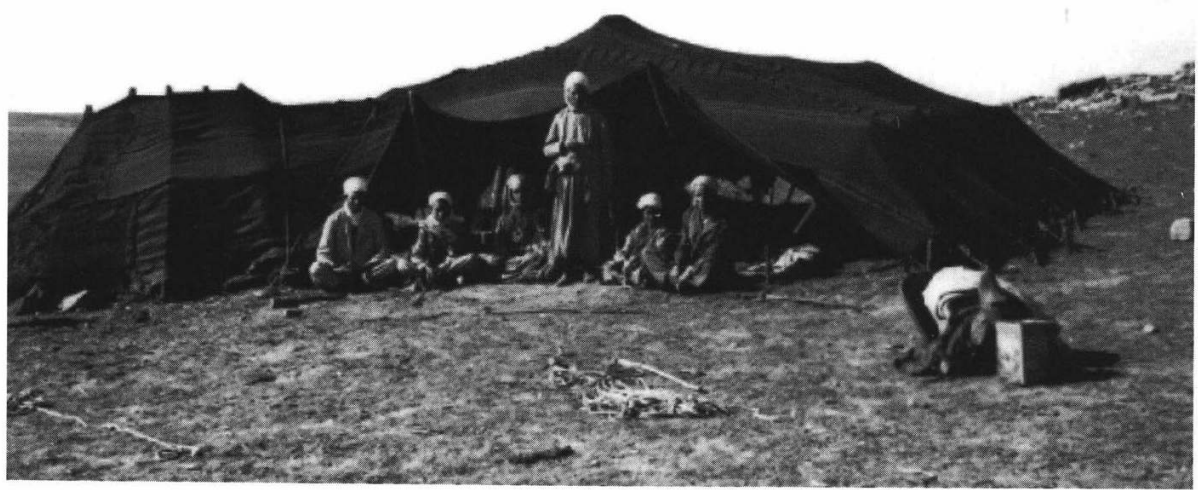

(photo Y. Bonète).

3 Le flij sert essentiellement à la confection du vélum de la tente des nomades qui annoncent leur identité par le choix et l'agencement des couleurs de ce tissage: entièrement noir ; noir et blanc ; rouge et noir ; brun et noir ; beige, blanc, noir, etc. Le nombre de flij d'un vélum est à peu près constant dans chaque tribu ; il définit l'espace vital de la famille nucléaire compte tenu de la division en deux sous la tente, opérée par une grande pièce de tissu tendue verticalement (draga); côté homme à droite en entrant, côté femme à gauche, avec l'espace cuisine. D'une moyenne de 7,50 m sur 0,70 $\mathrm{m}$ à $0,90 \mathrm{~m}$ de large par élément, il faut quatre à six flij-s cousus bord à bord pour une tente modeste (région des Larbâa ou des Amouri du nord du Sahara par exemple), alors 
que les tentes des nomades de l'Atlas marocain en altitude sont remarquablement plus longues et plus larges. Un vélum de flij-s en bon état peut résister à la pluie (les fibres se resserrent et deviennent imperméables) et à la neige. Sa protection sous de fortes insolations, est meilleure que celle de la tente en peau. Son usure, rapide dans un usage permanent de la tente (cinq ou six ans), nécessite des remplacements successifs des bandes les plus abîmées. En sorte qu'une famille nomade consacre constamment une partie de sa production de laine à la confection de flij-s et que le métier à terre est mis en œuvre toutes les fois que cela est possible (surtout à la belle saison et en rapport avec la disponibilité des femmes).

4 Les flij-s peuvent servir éventuellement à la confection des grands sacs pour transporter le grain sur les chameaux (ghrara) et occasionnellement de tapis de sol. Mais ces usages secondaires ne sont que des pis aller car les sacs à grains tissés eux aussi sur le métier à terre avaient leurs décors propres, parfois très richement élaborés (comme dans les Nemenchas). Les flij-s réutilisés comme tapis de sol, achetés neufs ou d'occasion à bon compte sur les marchés (vendus par les nomades en hiver pour payer leurs impôts ou acheter du grain) étaient surtout appréciés des sédentaires qui ne pratiquaient pas ce genre de tissage rustique et bon marché.

\section{BIBLIOGRAPHIE}

BONÈTE Y., "La tente des nomades Arbâ ${ }^{1}$ et Mekhalif ", Cahiers des Arts et Techniques d'Afrique du Nord, Tunis 1955, p ; 32-39.

BORG A., "La tente nomade dans la région de Gafsa", ibid, p. 61-75 et Ginestous P.

BORG P., "La tente dans la région de Kairouan", ibid, p. 49-60.

DELPY A., "La tente au Maroc", p. 15-23.

FEILBERG C.-G., La tente noire, Copenhague 1944, Nordiskforlag, 244 p.

GOLVIN L., Les arts populaires en Algérie, t. 1 : Les techniques de tissage, Alger, 1950, Publications du Gouvernement général de l'Algérie (voir p. 124-128 description du métier horizontal des nomades).

LouIs A., Nomades d'hier et d'aujourd'hui dans le sud tunisien, Aix-en-Provence, Édisud, 1975, 334 p. (voir p. 163-166).

MARTEL Ch., "La transhumance et la tente chez les Zlass (Tunisie)", Cahiers des Arts et Techniques d'Afrique du Nord, 1955, n 4, p. 46-48.

MASSABIE G, "La tente et la vie nomade dans le Nefzaoua", ibid, p. 76-80.

TоuсHоN A., "La tente nomade au Djebel Amour", ibid, p. 24-31. 
INDEX

Mots-clés : Arme, Artisanat 